\title{
Clear Zone Formation around Screws in the Early Postoperative Stages after Posterior Lumbar Fusion Using the Cortical Bone Trajectory Technique
}

\author{
Koshi Ninomiya, Koichi Iwatsuki, Yu-Ichiro Ohnishi, Toshika Ohkawa, Toshiki Yoshimine \\ Department of Neurosurgery, Osaka University Graduate School of Medicine, Suita, Japan
}

\begin{abstract}
Study Design: Retrospective study.
Purpose: To evaluate the initial fixation using the cortical bone trajectory (CBT) technique for posterior lumbar fusion through assessment of the clear zones around the screws and the risk factors involved.

Overview of Literature: Postoperative radiolucent zones (clear zones) are an indicator of poor conventional pedicle screw fixation. Methods: Between January 2013 and April 2014, 19 patients (8 men and 11 women) underwent posterior lumbar interbody fusion or posterior lumbar fusion using the CBT technique. A total of 109 screws were used for evaluation with measurement of the maximum insertional torque of last two screw rotations. Clear zone-positivity on plain radiographs was investigated 6 months after surgery. The relation between intraoperative insertional torque and clear zone-positivity was investigated by one-way analysis of variance. In addition, the correlation between clear zone-positivity and gender, age $(<75$ years old or $>75$ years old $)$, or operative stabilization level $(<2$ or $>3$ vertebral levels) was evaluated using the chi-square test.

Results: Clear zones were observed around six screws $(5.50 \%)$ in five patients $(26.3 \%)$. The mean insertional torque $(4.00 \pm 2.09$ inIbs) of clear zone-positive screws was lower than that of clear zone-negative screws $(8.12 \pm 0.50 \mathrm{in}$-lbs), but the difference was not significant. There was a significant correlation between clear zone-positivity and operative level of stabilization.

Conclusions: The low incidence of clear zone-positive screws indicates good initial fixation using the CBT technique. Multilevel fusions may be risk factors for clear zone generation.
\end{abstract}

Keywords: Cortical bone trajectory; Clear zone; Initial fixation

\section{Introduction}

The cortical bone trajectory (CBT) technique for lumbar vertebral fixation was first described by Santoni et al. [1] in 2009. CBT is more effective for initial fixation by maximizing screw-cortical bone contact, as compared to the traditional pedicle screw insertion. The results of a human cadaver study showed a 30\% increase in uniaxial yield pullout load and equivalency in mixed loading for the CBT screw, as compared with traditional pedicle screws [1]. Matsukawa et al. [2] reported a significant difference between the mean maximum intraoperative insertional torque of CBT screws and traditional screws. We also confirmed that the pars interarticularis is a very

Received Feb 16, 2015; Revised Mar 12, 2015; Accepted Mar 13, 2015

Corresponding author: Koshi Ninomiya

Department of Neurosurgery, Osaka University Graduate School of Medicine,

2-2 Yamadaoka, Suita, Osaka, Japan 565-0871

Tel: +81-6-6879-3652, Fax: +81-6-6879-3659, E-mail: k-ninomiya@nsurg.med.osaka-u.ac.jp 
important structure for the CBT technique through an in vivo torque study between spondylolysis and non-spondylolysis cases (unpublished observations).

However, a higher pullout strength and insertional torque does not always reflect a favorable initial fixation. Postoperative radiological evaluation may be needed for the initial fixation, with postoperative radiolucent zones around the screws (clear zones) as an indicator for poor conventional pedicle screw fixation.

In this study, we examined clear zones around CBT screws in postoperative radiographs taken at 6 months, and investigated the involved risk factors in posterior lumbar fusion cases.

\section{Materials and Methods}

This study was approved by the institutional ethics committee of Osaka University (approval number 14168).

Nineteen patients, including eight men (mean age, $59.5 \pm 15.9$ years; range, $37-80$ years) and 11 women (mean age, $64.3 \pm 12.0$ years; range, $36-78$ years), underwent posterior lumbar interbody fusion or posterior lumbar fusion for lumbar canal stenosis with or without degenerative spondylolisthesis using the CBT technique, at our institution between January 2013 and April 2014. A total of 109 screws were inserted into the lumbar or lumbosacral spine. One screw was malplaced medially at more than half of the screw diameter and was excluded from this study. Screws were inserted at the following lumbar and sacral levels: L1, $\mathrm{n}=2 ; \mathrm{L} 2, \mathrm{n}=10 ; \mathrm{L} 3, \mathrm{n}=22 ; \mathrm{L} 4, \mathrm{n}=38$; $\mathrm{L}$, $\mathrm{n}=31$; and $\mathrm{S} 1, \mathrm{n}=6$. Among all the screws included in this study, 61 screws were inserted for a $\leq 2$ level fusion and 48 screws were inserted for a $\geq 3$ level fusion.

CBT was performed under lateral fluoroscopy [3]. We used the isthmus of the lumbar lamina as an anatomical landmark for entry. We used microscopy for spinal root decompression because screws were placed $3 \mathrm{~mm}$ inside the isthmus in the pars interarticularis. The trajectory follows a cephalad and lateral path through the pedicle. Sacral screws were introduced from beneath the superior facet and inserted cephalad and laterally. Same-size tapping was performed for all screws. The screw diameter was $4.5 \mathrm{~mm}$ (Zodiac polyaxial screw, Alphatec Spine Inc., Tokyo, Japan) and the lengths were $25 \mathrm{~mm}$ and $30 \mathrm{~mm}$, and the pitch was $4 \mathrm{~mm}$. Polyetheretherketone spacers (NOVEL PEEK, Alphatec Spine Inc.) were used for posterior interbody fusion. Spinous processes removed for decompression were used for interbody and posterolateral bony fusion. The maximum insertional torque of the last two rotations of all the 109 screws was measured using an in-line dial indicator 584100 (Holmed Co., Franklin, MA, USA). The scale was modified by Alphatec Spine to measure 0 to 55 in-lbs $(1$ in-lbs $=0.113 \mathrm{Nm})$ in increments of 1 in-lbs.

The presence of clear zones was investigated at 6 months after surgery. As reported previously [4], when a 1-mm or greater circumferential radiographic lucency was observed around a screw on plain radiographs from two or more directions by more than two observers, the screw and patient were judged as clear zone-positive. All the clear zone-positive screws diagnosed by radiographs were confirmed by lumbar computed tomography.

The relationship between intraoperative insertional torque and clear zone-positivity was investigated by oneway analysis of variance for the assessment of risk factors for clear zone- positivity. In addition, the correlation between clear zone-positivity and gender, age $(<75$ years old or $\geq 75$ years old), or operative stabilization level ( $\leq 2$ or $\geq 3$ levels) was evaluated using the chi-square test. We chose 75 years as the division criterion because in Japan, people more than 75 years old are classified as late-stage elderly.

\section{Statistical analysis}

Statistical analyses were performed using one-way analysis of variance or chi-square test. Statistical significance was defined as $p<0.05$. We used JMP pro ver. 11 (SAS Institute Japan, Tokyo, Japan) for statistical analysis.

\section{Results}

Representative cases with clear zone-positive screws were shown in Figs. 1 and 2. Clear zones were observed around six screws $(5.50 \%)$ in five patients $(26.3 \%)$. Four patients were female. The mean age of patients with clear zonepositive screws was $66.4 \pm 13.9$ years; and mean age of the rest of the patients was $60.8 \pm 13.6$ years. The level of clear zone-positive screws were L1 ( $\mathrm{n}=1), \mathrm{L} 2(\mathrm{n}=3)$, and $S 1(n=2)$. Five of the screws were used in $\geq 3$ level fusion. One of the patients with clear zone-positive screws had mechanical lumbago and the rest were asymptomatic.

The mean insertional torque of the clear zone-positive

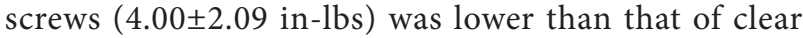
zone-negative screws ( $8.12 \pm 0.50$ in-lbs), but the difference 

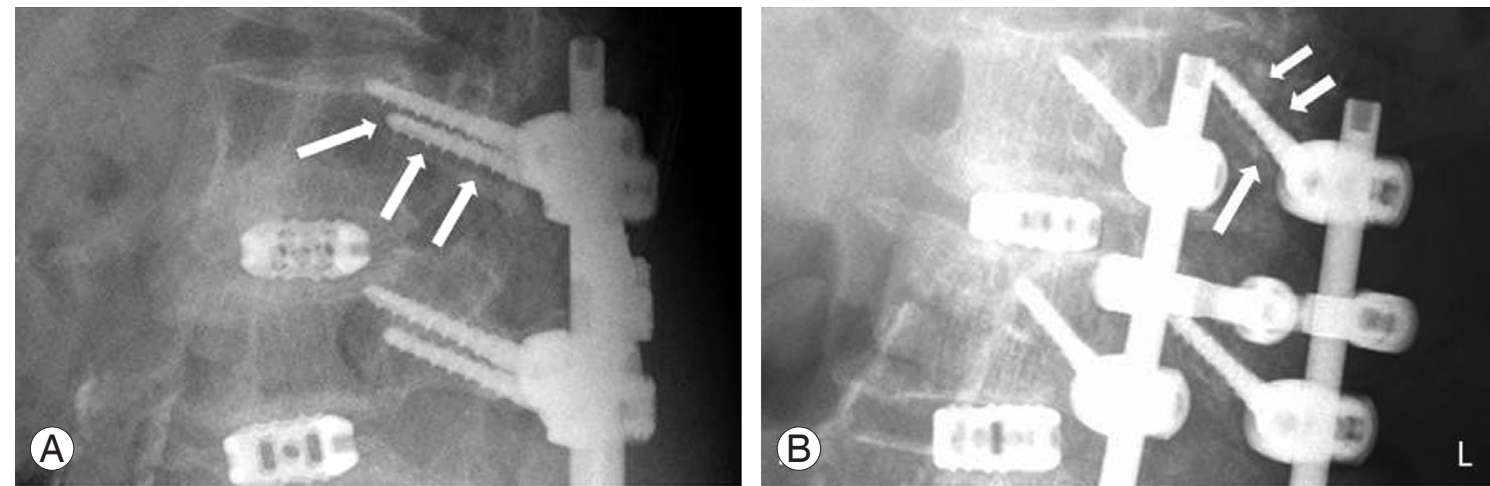

Fig. 1. Radiographs of a representative case. A 68-year-old woman who had a 4 level fusion. Lateral view (A) and oblique view (B) of plain radiographs show clear zones around left L2 cortical bone trajectory screw (arrows).
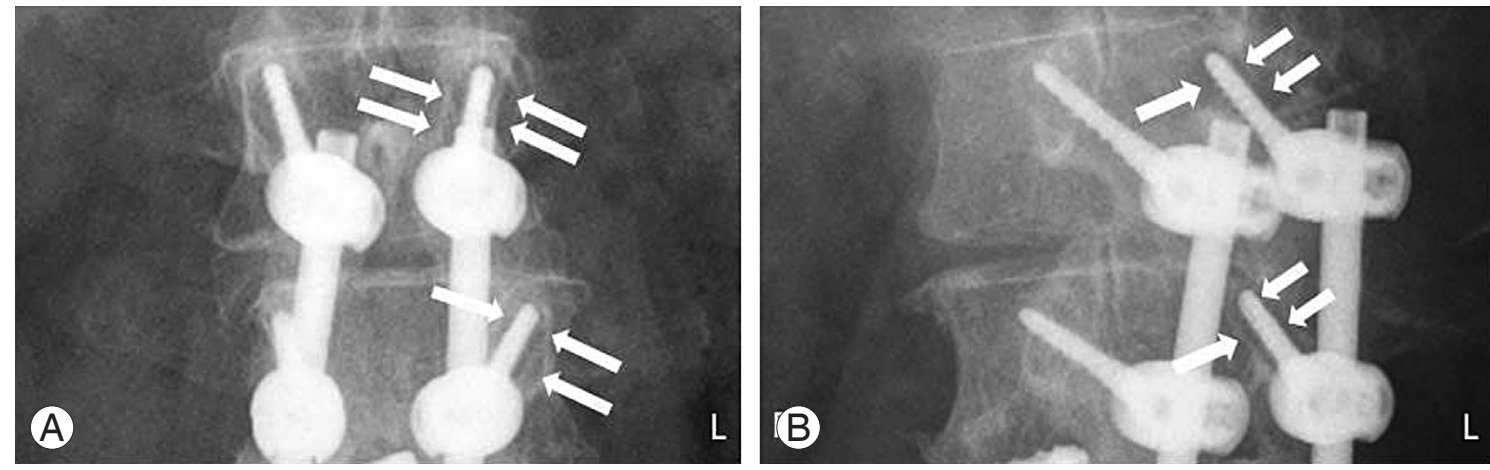

Fig. 2. Radiographs of a representative case. A 67-year-old woman who had 4 level fusion. Anterior-posterior view (A) and oblique view (B) of plain radiograph showed clear zones around left L1 and L2 cortical bone trajectory screws (arrows).

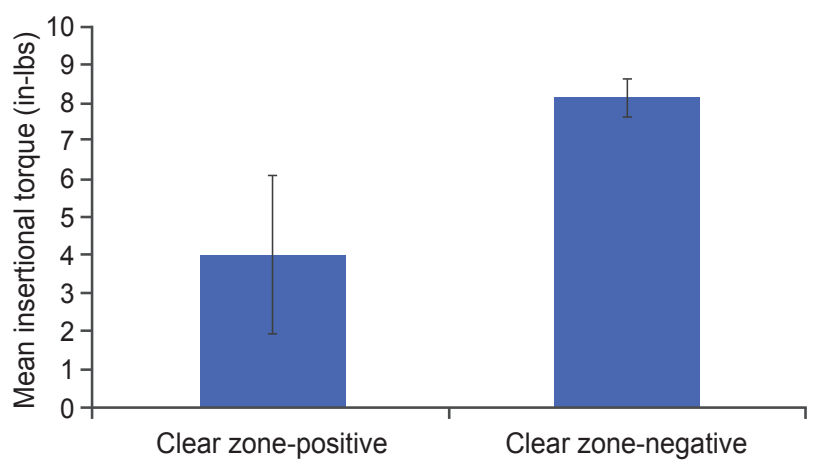

Fig. 3. Mean insertional torque of clear zone-positive and clear zonenegative screws. Values are presented as mean \pm standard error (error bars). There was no statistical difference between the two groups.

was not significant ( $p=0.06$ ) (Fig. 3). A comparison of the data obtained from the clear zone-positive and clear zonenegative screws was shown in Table 1 . There was significant correlation between clear zone-positivity and operative stabilization level ( $\leq 2$ or $\geq 3$ levels) ( $p=0.04$ ). However, clear zone-positivity and age ( $<75$ years old or $\geq 75$ years old) or gender showed no significant relationship.

\section{Discussion}

In the CBT technique, screws were stabilized mainly by posterior elements of solid cortical bone that is considered as a strong point for initial fixation. This advantage over conventional pedicle screws was demonstrated in an in vivo torque study [2]. We confirmed that the pars interarticularis is a very important structure for the CBT technique, as the in vivo insertional torque was approximately twice as high in non-spondylolysis as spondylolysis cases (unpublished observations). However, insertional torque may not predict screw loosening [5], which is reportedly caused primarily by cyclic toggling at the bone-screw interface [6]. The clear zone is a radiological lucency that is observed around the screw, and it is thought to appear due to a decreased fit between the screw and bone. The gap at the screw-bone interface disappears with the de- 
Table 1. Comparison of data between clear zone-positive and clear zone-negative screws

\begin{tabular}{|c|c|c|c|c|}
\hline Variable & Total & Clear zone-positive & Clear zone-negative & $p$-value \\
\hline No. of screws & 109 & 6 & 103 & - \\
\hline Sex & & & & 0.29 \\
\hline Male & 39 & 1 & 38 & \\
\hline Female & 70 & 5 & 65 & \\
\hline Age (yr) & & & & 0.59 \\
\hline$<75$ & 83 & 4 & 79 & \\
\hline$\geq 75$ & 26 & 2 & 24 & \\
\hline No. of fused levels & & & & 0.04 \\
\hline$<2$ & 61 & 1 & 60 & \\
\hline$>3$ & 48 & 5 & 43 & \\
\hline
\end{tabular}

crease of intervertebral mobility through the progression of bone union [4]. Thus, clear zones may indicate not only screw loosening, but also insufficient bone union $[7,8]$. Clear zones have been used to assess fixation in conventional pedicle screw fusion cases [4,9]. Therefore, we used clear zones around the CBT screws to assess fixation in this study.

Tokuhashi et al. [4] demonstrated that, although approximately two thirds of the clear zones disappeared at a final follow-up of $\geq 3$ years, clear zones around conventional pedicle screws were observed around $\geq 1$ screws in $41.1 \%$ of patients at 6 months after surgery. Wu et al. [9] analyzed 658 pedicle screws used to place Dynesys devices for dynamic stabilization in 126 patients with lumbar spondylosis. Their results indicated that 31 screws (4.7\%) in 25 patients (19.8\%) became loose in a mean follow-up period of 3 years; and fusion levels were $\leq 2$ vertebrate. In our study, which included longer fusion levels with 4.5$\mathrm{mm}$ diameter screws, six screws (5.5\%) in five patients (26.3\%) had $\geq 1$ clear zone-positive screws at 6 months. Though further study is needed, the current results suggested that the CBT technique might be superior to conventional methods with respect to the initial fixation.

The low incidence of clear zone-positive screws in CBT may be due to the posterior element. Giambini et al. [10] showed that the bone mineral density of the neural arch trabecula was maintained, regardless of the presence of a vertebral compression fracture. Thus, CBT screws may have strong resistance to postoperative share loading or micromotion, as compared to conventional screws.

Wu et al. [9] investigated the risk factors of screw loosening in conventional lumbar stabilization and showed that older patients and those with diabetes had higher rates of screw loosening. Furthermore, they identified more screws in the the lower vertebral body of the construct than the upper ( $72 \%$ vs. $28 \%$, respectively), unlike the findings in our study. We hypothesized that low intraoperative torque may cause clear zones around screws. The mean insertional torque of clear zone-positive screws was lower than that of clear zone-negative screws, but this difference was not significant $(p=0.06)$. Additional data is required to statistically confirm these results.

The incidence of clear zones around conventional pedicle screws was significantly higher when multiple levels were fused. Consistently, our results showed that $\geq 3$ level fusion was a risk factor for the presence of clear zones.

Longer follow-up of our cases was not conducted. However, according to previous reports, most loose screws appear during the early postoperative period ( $<6$ months) [11], and delayed-onset loosening is rare [12].

In a previous report, patient age of less than 55 years was proposed as a risk factor without adverse effects on clinical outcomes [13]. In this study, age ( $<75$ years old or $\geq 75$ years old) was not a risk factor of clear zone generation. Our study was limited by the number of screws examined, and further study is needed to confirm that age, gender, or low insertional torque might be a risk factor for clear zone formation.

\section{Conclusions}

We evaluated initial fixation using the CBT technique by clear zone-positivity. Low incidence of clear zone-positive screws demonstrated good initial fixation using the CBT 
technique. Multilevel fusion might be a risk factor of clear zone generation.

\section{Conflict of Interest}

No potential conflict of interest relevant to this article was reported.

\section{References}

1. Santoni BG, Hynes RA, McGilvray KC, et al. Cortical bone trajectory for lumbar pedicle screws. Spine J 2009;9:366-73.

2. Matsukawa K, Yato Y, Kato T, Imabayashi H, Asazuma T, Nemoto $\mathrm{K}$. In vivo analysis of insertional torque during pedicle screwing using cortical bone trajectory technique. Spine (Phila Pa 1976) 2014;39: E240-5.

3. Iwatsuki K, Yoshimine T, Ohnishi Y, Ninomiya K, Ohkawa T. Isthmus-guided cortical bone trajectory for pedicle screw insertion. Orthop Surg 2014;6:2448.

4. Tokuhashi Y, Matsuzaki H, Oda H, Uei H. Clinical course and significance of the clear zone around the pedicle screws in the lumbar degenerative disease. Spine (Phila Pa 1976) 2008;33:903-8.

5. Law M, Tencer AF, Anderson PA. Caudo-cephalad loading of pedicle screws: mechanisms of loosening and methods of augmentation. Spine (Phila Pa 1976) 1993;18:2438-43.

6. Okuyama K, Abe E, Suzuki T, Tamura Y, Chiba M, Sato K. Can insertional torque predict screw loosening and related failures? An in vivo study of pedicle screw fixation augmenting posterior lumbar interbody fusion. Spine (Phila Pa 1976) 2000;25:858-64.

7. Sanden B, Olerud C, Petren-Mallmin M, Larsson S. Hydroxyapatite coating improves fixation of pedicle screws: a clinical study. J Bone Joint Surg $\mathrm{Br}$ 2002;84:387-91.

8. Sanden B, Olerud C, Johansson C, Larsson S. Improved bone-screw interface with hydroxyapatite coating: an in vivo study of loaded pedicle screws in sheep. Spine (Phila Pa 1976) 2001;26:2673-8.

9. Wu JC, Huang WC, Tsai HW, et al. Pedicle screw loosening in dynamic stabilization: incidence, risk, and outcome in 126 patients. Neurosurg Focus 2011; 31:E9.

10. Giambini H, Salman Roghani R, Thoreson AR, Melton LJ 3rd, An KN, Gay RE. Lumbar trabecular bone mineral density distribution in patients with and without vertebral fractures: a case-control study. Eur Spine J 2014;23:1346-53.

11. Schaeren S, Broger I, Jeanneret B. Minimum fouryear follow-up of spinal stenosis with degenerative spondylolisthesis treated with decompression and dynamic stabilization. Spine (Phila Pa 1976) 2008;33: E636-42.

12. Stoll TM, Dubois G, Schwarzenbach O. The dynamic neutralization system for the spine: a multi-center study of a novel non-fusion system. Eur Spine J 2002; 11 Suppl 2:S170-8.

13. Ko CC, Tsai HW, Huang WC, et al. Screw loosening in the Dynesys stabilization system: radiographic evidence and effect on outcomes. Neurosurg Focus 2010;28:E10. 